\title{
Prevalence and risk factors of sexual dysfunction in healthy women in Turkey
}

\author{
Meral Kıliç
}

Ataturk University Faculty of Health Sciences, Erzurum, Turkey.

\begin{abstract}
Objectives: This is a cross sectional study conducted in order to determine sexual dysfunction in healthy women and risk factors.

Patients and methods: The population of the study consisted of 282 women. The whole of the population, without sample selection, was included in the study. For data, questionnaire and Female Sexual Function Index-FSFI, whose Turkish validity and reliability study was conducted, were used. Student $\mathrm{t}$ and chi-square significant tests and logistic regression analysis were used to carry out statistical analysis.

Results: It was found that $35.8 \%$ of 282 women who participated in the study were in the age range of $30-39$ years, $54.6 \%$ had high school educational level or above, and 59.6\% worked. Prevalence was determined as 53.2\% FSFI score $<26$ according to Female Sexual Function Index FSFI; 23\% of the women had complaints about urinary incontinence UI. According to logistic regression results, it is determined that $\mathrm{CFB}$ risk is increased in patients with age and urination problem. It was determined that there was no significant correlation between income, number of children, prceived economic status, dyspareunia, having problem with the partner, experiencing premenstrual syndrome, and SD.

Conclusion: In this study, approximately half of healthy women had SD and development of SD was affected based on some descriptive characteristics. As sexual life was considered as a factor increasing life quality, it was thought that it is fairly important to discuss the questioning of problems related to sexual life for systematic evaluation of patients, as well.
\end{abstract}

Keywords: SD, risk factors, prevalence, Turkey.

DOI: https://dx.doi.org/10.4314/ahs.v19i3.38

Cite as: Kllic M. Prevalence and risk factors of sexual dysfunction in bealthy women in Turkey. Afri Health Sci. 2019;19(3): 26232633. https://dx.doi.org/10.4314/ahs.v19i3.38

\section{Background}

Sexual dysfunction in women is a public health issue with many physical and psychological outcomes, that affects women's quality of life ${ }^{1}$. Sexuality is a complex process related to neurological, vascular and endocrine systems. It also includes familial, social, and religious beliefs ${ }^{2}$.

Female sexual dysfunction FSD is a common problem and negatively influences life quality. Sexual dysfunction
Correspondence author:
Meral Kilıç,
Department of Midwifery,
Faculty of Health Science,
Ataturk University,
Erzurum, Turkey.
Email: m_kavak25@hotmail.com;
meral.kilic@atauni.edu.tr

is defined as a permanent or recurrent decrease in sexual desire or arousal, having difficulty/insufficiency with success of achieving orgasm, and feeling pain during sexual intercourse ${ }^{3}$. SD has been stated as a sexual problem that adult women may experience at the rate of $40-45 \%$ in any time of their lives ${ }^{3}$. Complex interaction of several genetic, biological, psychological, social, and cultural factors play a role in etiology of $\mathrm{SD}^{4-6}$. The most common risk factors of SD are general health condition of individuals, presence of diabetes mellitus, presence of cardiovascular disorder, coexistence of other genitourinary disorders, psychiatric and psychological disorders, other chronic disorders, and socio-demographic characteristics ${ }^{3}$.

Sexual dysfunction may significantly affect individual's mood, self-confidence, life quality and may cause breakdown of interpersonal relationship and emotional stress ${ }^{7}$. Sexual dysfunction may be physically worrying, emotionally stressful, and socially destructive for several women ${ }^{8}$.

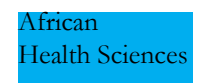

(C) 2019 Klliç M. Licensee African Health Sciences. This is an Open Access article distributed under the terms of the Creative commons Attribution License (https://creativecommons.org/licenses/BY/4.0), which permits unrestricted use, distribution, and reproduction in any medium, provided the original work is properly cited. 
In a previous study, it was stated that physical and emotional health of women experiencing sexual dysfunction was worse ${ }^{9}$. In another study, it was found that if a woman was not comfortable with sexuality, this resulted in interparental conflict and divorce and reproduction was influenced $^{2}$. Sexual dysfunction between spouses has been reported as the second underlying reason for divorce in Muslim countries ${ }^{10}$.

As it is in several cultures, sexuality is an issue that is also assumed as a taboo, ignored by women, and is not considered very much by healthcare professionals in Turkey. This condition may make negative impacts on life quality deeper by causing sexual problems to become more complex and harder to solve. However, it is very important to discuss questioning about sexual life in systematic evaluation of patients when sexual life is considered as a factor that enhances quality of life. Therefore, the study was conducted in order to examine sexual dysfunction and reasons in healthy women in age group of 15-49 years and to draw attention of healthcare professionals on this issue.

\section{Objectives}

Sexual dysfunction SD is a complex health problem affected by numerous anatomic, psychological, medical, and social factors. This is a cross sectional study conducted in order to determine sexual dysfunction in healthy women; and its risk factors.

\section{Material and methods \\ Study design}

This study was a cross sectional one conducted in order to determine sexual dysfunction and its reasons in healthy women. The data were collected from women who attended the gynecology outpatient clinic of a University Hospital between 1 April and 30 June 2016. Inclusion criteria of the sample were determined as being older than 20 years, agreeing to participate in the study, married, not breastfeeding, not being pregnant, and not going through menopause. The women who were diagnosed with any type of systemic disorder, such as diabetes, hypertension, coronary artery disease, etc., using medicine continuously due to any reason, and were at one year period of postpartum were excluded from the study. The sample of the study consisted of 282 women who attended the out- patient clinic for various complaints or control between specified date and met the criteria.

\section{Instruments and measures}

The data were collected by using face-to-face interview technique via a questionnaire developed by the researchers after the relevant literature review ${ }^{2,10-13}$. A questionnaire and Female Sexual Function Index-FSFI, whose Turkish validity and reliability study was conducted, were used as data collection tool ${ }^{14}$. In the questionnaire, risk factors that may influence socio-demographic, obstetric, and sexual functions of the women were questioned. Age, education, employment status, income, health insurance, and duration of marriage were evaluated as demographic characteristics. For obstetric characteristics, number of children, type of birth, and status of using family planning method were assessed. Urinary incontinence, vaginal route infection, pain during sexual intercourse (dyspareunia), premature ejaculation problem of partner, erection problem of partner, and experiencing premenstrual syndrome were evaluated as factors related to sexual dysfunction.

FSFI is a Likert type scale consisting of 19 items and evaluating sexual dysfunction in women. Validity and reliability study of FSFI was conducted by Rosen et al. ${ }^{14}$, Cronbach's alpha coefficient was 0.82 and test reliability was $0.79-0.86$. Scale's Turkish validity and reliability analysis was conducted by Oksuz and Malhan ${ }^{15}$. Scale consists of 6 separate titles: desire, arousal, lubrication, orgasm, satisfaction, and pain. Each title in this scale was scored between 0 or 1 and 6 . Score range of overall scale was between 2 minimum score and 36 maximum score. High score indicates better function. In this study Cronbach's alpha coefficient was 0.81 and existence of sexual dysfunction in this study was also accepted in women who had a score of 26.55 and below ${ }^{16}$.

\section{Data analysis}

The data were evaluated by using SPSS 10.0 packaged software and complementary statistics of the data were assessed by using percentage distribution and mean. Student $t$ and chi-square significance tests were used in order to determine possible correlations between dependent and independent variables. Logistic regression analysis method was utilized for detecting risk factors that may cause sexual dysfunction. 


\section{Ethical principles}

In order to conduct this study, ethical approval of Atatürk University Institutional of Health Sciences Review Board according to the Declaration of Helsinki IRB No. CMUH-2016/03/9 was received. As the questions had to be answered voluntarily, we informed the participants that they were free in participating in the study and we assured their willingness and voluntariness. There after, the participants were informed and their questions were answered about the study. They were also informed that they could withdraw from the study anytime, and this would not care received at the clinic.

\section{Results}

As descriptive characteristics of the women participating in the study were examined; it was found that duration of marriage was $14.58 \pm 10.40$, the number of children was $2.23 \pm 0.99$, and frequency of intercourse was $1.08 \pm 068$; $35.8 \%$ of the women were in age group of $30-39$ years, $54.6 \%$ of the women and $69.5 \%$ of their husbands had high school level and above education, $59.6 \%$ of the women were employed, $54.6 \%$ of their husbands were civil servants, and $87.2 \%$ stated their perceived economic condition as medium-good; $72.5 \%$ of the women also expressed that they used modern method, and $71.5 \%$ had had normal delivery Table 1.

\begin{tabular}{|l|l|l|}
\hline \multicolumn{2}{|l|}{ Table 1. Distribution of women's descriptive characteristics } \\
\hline Characteristics & Mean & sd \\
\hline Duration of marriage & 14.58 & 10.40 \\
\hline Number of children & 2.23 & 0.99 \\
\hline Frequency of intercourse Week & 1.08 & 0.68 \\
\hline Age & & \\
$20-29$ & 72 & 25.5 \\
30-39 & 101 & 35.8 \\
40-49 & 76 & 27.0 \\
50 and older & 33 & 11.7 \\
\hline Educational Level & & \\
Secondary school and below & 128 & 45.4 \\
High school and above & 154 & 54.6 \\
\hline Educational level of Husband & & \\
Secondary school and below & 86 & 30.5 \\
High school and above & 196 & 69.5 \\
\hline Employment Status & & \\
Employed & 114 & 40.4 \\
Unemployed & 168 & 59.6 \\
\hline Husband's Job & & \\
Self employed & 128 & 45.4 \\
Civil servant & 154 & 54.6 \\
\hline Perceived Economic condition & & \\
High & 36 & 12.8 \\
Medium + low & 246 & 87.2 \\
\hline Status of Using Method n:262 & 190 & 72.5 \\
Modern method & 72 & 27.5 \\
\hline Withdrawal & 181 & 71.5 \\
\hline Type of Birth n: 253 & 28.5 \\
Normal & 72 & 53.2 \\
Cesarean & & 36.5 \\
\hline IFSI SCORE & \\
Low 26 points and less & & \\
Medium+ high 27 points and above & 103 & \\
\hline & & \\
\hline
\end{tabular}


When risk factors that may cause sexual dysfunction in women were examined; $23 \%$ had urinary incontinence, $26.6 \%$ had symptom of urinary tract infection, and $22.6 \%$ experienced pain during sexual intercourse. It was deter- mined that husbands of $15.7 \%$ of women had premature ejaculation problem, husbands of $7.1 \%$ had erection problem, $8.6 \%$ had problem with their husbands, and $37.6 \%$ experienced premenstrual syndrome Table 2.

\begin{tabular}{|l|l|l|}
\hline Table 2. Distribution of risk factors to cause sexual dysfunction \\
\hline Risk Factors & Number & $\%$ \\
\hline Experiencing urinary incontinence & 65 & 23 \\
\hline Symptom of urinary tract infection & 75 & 26.6 \\
\hline Experiencing pain during sexual intercourse dyspareunia & 63 & 22.6 \\
\hline Premature ejaculation problem of husband & 44 & 15.7 \\
\hline Having erectile problem & 20 & 7.1 \\
\hline Having problem with husband & 24 & 8.6 \\
\hline Experiencing premenstrual syndrome & 106 & 37.6 \\
\hline
\end{tabular}

In Table 3, it was found that women's duration of marriage, age, education of women and their husbands, using method, and type of birth were correlated with experiencing sexual dysfunction, but there was not a significant correlation between income level, the number of children, and perceived economic status and sexual dysfunction $\mathrm{p}>0.05$ Table 3 .
According to correlation of sexual dysfunction with descriptive characteristics and logistic regression analysis of risk factors; age posed a risk for sexual dysfunction, but duration of marriage, income, the number of children, educational level of woman and her husband, employment status, perceived economic condition, using method, and type of birth were determined not to pose a risk for sexual dysfunction Table 3 
Table 3: Correlation of female sexual dysfunction with descriptive characteristics and logistic regression analysis of risk factors

\begin{tabular}{|c|c|c|c|c|}
\hline \multirow{2}{*}{$\begin{array}{l}\text { Descriptive } \\
\text { Characteristics }\end{array}$} & \multicolumn{2}{|c|}{ Sexual Dysfunction } & \multirow{2}{*}{$\begin{array}{l}\text { Significance } \\
\text { test }\end{array}$} & \multirow{2}{*}{$\begin{array}{l}\text { OR } \\
95 \% \\
\text { confidence interval }\end{array}$} \\
\hline & $\begin{array}{l}\text { Yes } \\
\mathbf{x} \pm \text { SD }\end{array}$ & $\begin{array}{l}\text { No } \\
\mathbf{x} \pm \mathbf{S D}\end{array}$ & & \\
\hline Duration of Marriage & $1,724 \pm 1.101$ & $2.213 \pm 1.106$ & $\begin{array}{l}\text { t: }-3.585 \\
\text { p: } \mathbf{. 0 0 0}\end{array}$ & $\begin{array}{l}.105 .498-1.647 \\
\text { p: } 746\end{array}$ \\
\hline Income & $1.153 \pm, 3615$ & $1.106 \pm, 3103$ & $\begin{array}{l}\text { t: } 1.064 \\
\text { p:..288 }\end{array}$ & $\begin{array}{l}304.332-1.855 \\
\text { p: } 581\end{array}$ \\
\hline Number of children & $2.150 \pm 1.766$ & $2.178 \pm, 5549$ & $\begin{array}{l}\mathrm{t}:-155 \\
\mathrm{p}: .877\end{array}$ & $\begin{array}{l}2.724 .961-1.599 \\
\text { p: } 099\end{array}$ \\
\hline $\begin{array}{l}\text { Age } \\
40 \text { years and below } \\
40 \text { years and above }\end{array}$ & $\begin{array}{l}10670.7 \\
6750.8\end{array}$ & $\begin{array}{l}4429.3 \\
6549.2\end{array}$ & $\begin{array}{l}X^{2}=11.737 \\
\text { p: .000 }\end{array}$ & $\begin{array}{l}2.3371 .432-3.815 \\
\text { p:.001 }\end{array}$ \\
\hline $\begin{array}{l}\text { Educational level of } \\
\text { woman } \\
\text { Secondary school and } \\
\text { below } \\
\text { High school and above }\end{array}$ & $\begin{array}{l}5442.2 \\
9662.3\end{array}$ & $\begin{array}{l}7457.8 \\
5837.7\end{array}$ & $\begin{array}{l}X^{2}=13.399 \\
\text { p: .001 }\end{array}$ & $\begin{array}{l}.810 .373-1.760 \\
\text { p: } .595\end{array}$ \\
\hline $\begin{array}{l}\text { Husband's educational } \\
\text { level } \\
\text { Secondary school and } \\
\text { below } \\
\text { High school and above }\end{array}$ & $\begin{array}{l}3034.9 \\
12061.2 \\
\end{array}$ & $\begin{array}{l}5665.1 \\
7638.8 \\
\end{array}$ & $\begin{array}{l}X^{2}=16.657 \\
\text { p:. } 000\end{array}$ & $\begin{array}{l}.616 .291-1.306 \\
\text { p: } .206\end{array}$ \\
\hline $\begin{array}{l}\text { Employment status } \\
\text { Unemployed } \\
\text { Employed }\end{array}$ & $\begin{array}{l}6960.5 \\
8148.2 \\
\end{array}$ & $\begin{array}{l}4539.5 \\
8751.8 \\
\end{array}$ & $\begin{array}{l}X^{2}=4.135 \\
p: .052\end{array}$ & $\begin{array}{l}.786 .398-1.549 \\
\text { p: } .486\end{array}$ \\
\hline $\begin{array}{l}\text { Perceived economic } \\
\text { status } \\
\text { High } \\
\text { Medium+low }\end{array}$ & $\begin{array}{l}12651.2 \\
2466.7\end{array}$ & $\begin{array}{l}12048,8 \\
1233.3\end{array}$ & $\begin{array}{l}X^{2}=3.010 \\
p: .107\end{array}$ & $\begin{array}{l}.568 .240-1.347 \\
\text { p: } .200\end{array}$ \\
\hline $\begin{array}{l}\text { Status of Using } \\
\text { Method n:262 } \\
\text { Modern method } \\
\text { Withdrawal } \\
\end{array}$ & $\begin{array}{l}11359.5 \\
3041.7 \\
\end{array}$ & $\begin{array}{l}7740.5 \\
4258.3 \\
\end{array}$ & $\begin{array}{l}X^{2}=6.679 \\
\text { p: .012 }\end{array}$ & $\begin{array}{l}.1 .508 .815-2.789 \\
\text { p: } .191\end{array}$ \\
\hline $\begin{array}{l}\text { Type of Birth } \mathbf{n : ~} \mathbf{2 5 3} \\
\text { Normal } \\
\text { Cesarean }\end{array}$ & $\begin{array}{l}8547.0 \\
4562.5\end{array}$ & $\begin{array}{l}9653.0 \\
2737.5\end{array}$ & $\begin{array}{l}X^{2}=4.979 \\
\text { p: .027 }\end{array}$ & $\begin{array}{l}2.608 .277-1.132 \\
\text { p: } .394\end{array}$ \\
\hline
\end{tabular}

It was found that experiencing sexual dysfunction was correlated with women who had urinary incontinence problem, symptom of urinary tract infection, whose husband had premature ejaculation and erection problem, but there was no significant correlation between experiencing pain during sexual intercourse, having problem with husband, and premenstrual syndrome and sexual dysfunction Table 4.
According to correlation of female sexual dysfunction with risk factors and logistic regression analysis of risk factors; it was determined that those having urinary incontinence posed a risk for sexual dysfunction, but those who had symptom of urinary tract infection, had pain problem during sexual intercourse, whose husband had premature ejaculation and erection problem, who had problem with their husband and experiencing premenstrual syndrome did not have a risk for sexual dysfunction Table 4. 
Table 4: Correlation of female sexual dysfunction with risk factors and logistic regression analysis

\begin{tabular}{|c|c|c|c|c|}
\hline \multirow[b]{2}{*}{$\begin{array}{l}\text { Descriptive } \\
\text { Characteristics }\end{array}$} & \multicolumn{2}{|c|}{ Sexual Dysfunction } & \multirow{2}{*}{ Significance test } & \multirow{2}{*}{$\begin{array}{l}\text { OR } \\
95 \% \text { confidence interval }\end{array}$} \\
\hline & Yes & No & & \\
\hline $\begin{array}{l}\text { Experiencing urinary } \\
\text { incontinence } \\
\text { Yes } \\
\text { No }\end{array}$ & $\begin{array}{l}1827.7 \\
13260.8\end{array}$ & $\begin{array}{l}4772.3 \\
8539.2\end{array}$ & $\begin{array}{l}X^{2}=22.059 \\
\text { p: .000 }\end{array}$ & $\begin{array}{l}.263 .131-.263 \\
\text { p: .000 }\end{array}$ \\
\hline $\begin{array}{l}\text { Symptom of urinary tract } \\
\text { infection } \\
\text { Yes } \\
\text { No }\end{array}$ & $\begin{array}{l}3141.3 \\
11957.5\end{array}$ & $\begin{array}{l}4458.7 \\
8842.5\end{array}$ & $\begin{array}{l}X^{2}=5.770 \\
\text { p: .021 }\end{array}$ & $\begin{array}{l}.766 .457-1.781 \\
\text { p: } .766\end{array}$ \\
\hline $\begin{array}{l}\text { Experiencing pain during } \\
\text { sexual intercourse } \\
\text { Yes } \\
\text { No }\end{array}$ & $\begin{array}{l}3250.8 \\
11853.9\end{array}$ & $\begin{array}{l}3149.2 \\
10146.1\end{array}$ & $\begin{array}{l}X^{2}=.187 \\
\text { p: } .670\end{array}$ & $\begin{array}{l}1.255645-2.439 \\
\text { p: } .504\end{array}$ \\
\hline $\begin{array}{l}\text { Premature ejaculation } \\
\text { problem of husband } \\
\text { Yes } \\
\text { No }\end{array}$ & $\begin{array}{l}1636.4 \\
13456.5\end{array}$ & $\begin{array}{l}2863.6 \\
10343.5\end{array}$ & $\begin{array}{l}X^{2}=6.071 \\
\text { p: .020 }\end{array}$ & $\begin{array}{l}.578273-1.221 \\
\text { p: .151 }\end{array}$ \\
\hline $\begin{array}{l}\text { Male erectile problem } \\
\text { Yes } \\
\text { No }\end{array}$ & $\begin{array}{l}630.0 \\
14455.0 \\
\end{array}$ & $\begin{array}{l}1470.0 \\
11845.0 \\
\end{array}$ & $\begin{array}{l}X^{2}=4.650 \\
\text { p: .037 }\end{array}$ & $\begin{array}{l}.526 .173-1.594 \\
\text { p: .256 }\end{array}$ \\
\hline $\begin{array}{lll}\text { Having problem with } \\
\text { husband } \\
\text { Yes } \\
\text { No }\end{array}$ & $\begin{array}{l}1666.7 \\
13451.9\end{array}$ & $\begin{array}{l}833.3 \\
12448.1\end{array}$ & $\begin{array}{l}\mathrm{X}^{2}=1.913 \\
\mathrm{p}: .202\end{array}$ & $\begin{array}{l}2.589 .952-7.043 \\
\text { p: .062 }\end{array}$ \\
\hline $\begin{array}{l}\text { Experiencing } \\
\text { premenstrual syndrome } \\
\text { Yes } \\
\text { No }\end{array}$ & $\begin{array}{l}5249.1 \\
9855.7\end{array}$ & $\begin{array}{l}5450.9 \\
7844.3\end{array}$ & $\begin{array}{l}\mathrm{X}^{2}=1.166 \\
\mathrm{p}: .325\end{array}$ & $\begin{array}{l}.832 .485-1.427 \\
\text { p: } .504\end{array}$ \\
\hline
\end{tabular}

\section{Discussion}

Sexual dysfunction is an important community health problem that affects women more than $\operatorname{men}^{17}$. Sexual dysfunction is a multidisciplinary dysfunction, which affects the physical, mental and social condition of wom$\mathrm{en}^{1}$. Prevalence of SD in the present study was found as $53.2 \%$. Prevalence of SD in previous studies conducted in Turkey was reported as $52.5 \%{ }^{18}, 46.9 \%{ }^{19}$, and $48.3 \%{ }^{15}$. In studies on different cultures, SD was similarly determined in $43 \%$ of women by Laumann et al. ${ }^{12}$, in $60 \%$ of Chinese women ${ }^{20}$, in $67.8 \%$ of Egyptian women between the ages $18-55^{21}$, in $13.3 \%-79.3 \%$ of Brazilian women ${ }^{21}$ in $56.8 \%$ of sexually active 5391 women aged between 40 59 years in Latin America ${ }^{22}$. In addition, numerous studies conducted on sexual dysfunction in Muslim countries show parallelism with findings from Turkey and European countries. It was found that $29.6 \%$ of Malay wom$\mathrm{en}^{5}, 31.5 \%$ of Iranian women ${ }^{23}$, and $68.9 \%$ of Egyptian women experienced at least one or more sexual problem. Results of the study make us think that female sexual dysfunction is a common poblem. High incidence of SD in the present study might be caused by neglect of sexual 
dysfunction, conservative beliefs, and widespread lack of information about sexuality in Turkey.

It was determined in the literature that low education level increases the risk of sexual dysfunction. ${ }^{1,224-26}$ In this study, along with a statistically significant correlation between the education level of women and their spouses and the level of sexual dysfunction occurrence, it was also stated that as education level increases, so does the frequency of sexual dysfunction occurrence. Results of the study conducted by Ismail et al. ${ }^{26}$ are similar to our ours, they both state that patients with a high education level exhibit a more frequent sexual dysfunction occurrence. In another study, when women with sexual dysfunction were compared with women who do not have sexual dysfunction, high education level was found to be the only criteria for the dysfunction. ${ }^{27}$ In Turkey, women with a high education level are employed in jobs with a high-stress level such as teachers and nurses. This chronic stress has a negative effect on gender and sexual hormones. ${ }^{28}$ Furthermore, women with higher education level may have a tendency towards breaking the taboos and openly revealing their sexual problems. ${ }^{27}$

In the present study, using modern contraceptive methods was determined to influence development of SD. It is remarkable that results of study, in which correlation between using contraction and SD was investigated, in the literature were contradictory. While there was no significant correlation between using method and SD in some studies ${ }^{23,29}$ significant correlation was also found in some studies similar to results of the present study. ${ }^{20,30,31}$ Using contraception may reduce anxiety resulted from unintended pregnancy during sexual intercourse and may had a positive effect on woman's sexual function. Further research is required to confirm and explain the effect of using methods on sexuality. ${ }^{30}$

In the studies conducted previously, it was observed that as the age progresses, so does the risk of sexual dysfunction occurrence. ${ }^{1,17,30}$ In this study, along with a significant correlation between the age of women and the occurrence of sexual dysfunction, it was also stated that the frequency of sexual dysfunction occurrence decreases as the age progresses. Results of the study conducted by Fajewonyomi et $\mathrm{al}^{32}$ are similar to our ours, it was observed that younger women have a higher risk of sexual dysfunction occurrence. Increase in the sexual dysfunc- tion occurrence with the progressing age is thought to be related with the hormonal changes during the menopause. With the reduced estrogen levels in the circulatory system, various levels of vaginal atrophy occur ${ }^{1,27,32}$ Physiological changes due to the progression of age do not necessarily mean that sexual intercourse is hard or impossible. Effects of age progression on sexual functions are mostly related to psychological, pharmacological and disease factors ${ }^{26,32}$.

Urinary incontinence UI has a negative effect on female sexuality ${ }^{33}$. In the study of Salonianin et al. ${ }^{34}$ the rate of sexual dysfunction was reported as $46 \%$ in women with UI. Being psychologically distressed, concerns about urinary incontinence during sexual intercourse, and feeling embarrassed because of smell have been indicated as the reason of sexual dysfunction ${ }^{33,35}$. In the present study, there was correlation between SD development and urinary incontinence, urinary incontinence was found as a risk factor for SD in logistic regression analysis carried out with other variables. It was reported in a previous study that sexual complaints were strongly correlated with UI, especially women with UI had lower libido, more vaginal dryness and dyspareunia complaint compared to those without $\mathrm{UI}^{36}$. Another study indicates that women with UI had low sexual activity ${ }^{37}$. In a study conducted by Zincir et al., it is stated that women with severe urinary incontinence have a low score in the Sexual Function Index for Women and poor sexual functions ${ }^{38}$. In a study conducted by Grzybowska et al. ${ }^{39}$ it is stated that women with severe and mid-level stress urinary incontinence have a poor sexual function quality. In a study conducted by Dos Santos et al. ${ }^{40}$ on nulliparous athletes, it is stated that women with urinary incontinence have 2.7 times more sexual desire problems, compared to women who do not have this problem. In current studies, the reason for positive correlation between SD and UI was indicated as the effect of UI on life quality, especially it posed a barrier on satisfaction of women, having coital incontinence, with sexual life. The correlation between SD and UI was reported to develop as a result of extremely active bladder, UI, and pelvic prolapse, in addition to hormone deficiencies that affect pelvic organs ${ }^{41}$.

Some characteristics and problems related to women's husband may be a risk factor towards SD. Jiann et al. ${ }^{42}$ determined that there was a significant correlation between 
male erectile disorder and female SD. Advanced age of husband ${ }^{17,43,44}$ premature ejaculation ${ }^{17,45}$ and erectile disorder $^{17,23,45}$ are stated as risk factors for SD. In the present study, a significant correlation was found between having husband with premature ejaculation problem and erectile disorder and developing SD.

Another factor affecting prevalence of SD is type of birth. In this study, a significant correlation was determined between type of birth and SD. Results of some previous study showed similarity with results of the present study and while it was reported that delay for starting sexual intercourse, dyspareunia, and sexual problems were correlated with vaginal delivery with intervention, episiotomy etc., and type of birth increased these mentioned risks, had a negative effect on sexual activity. ${ }^{46,47}$ Some studies indicated that there was no significant correlation between type of birth and episiotomy with time of starting postpartum sexual intercourse, sexual satisfaction, arousal, frequency of sexual intercourse, and dyspareunia; and dyspareunia was correlated only with breastfeeding ${ }^{48-50}$. Similarly, there are studies determining that a significant correlation was not found between sexual function with normal vaginal birth and cesarean section birth, women with cesarean section started postpartum sexual intercourse earlier than women who gave normal vaginal delivery and there was also variation between these correlations ${ }^{51}$.

In the present study, income was determined not to influence SD. Similar to result of the present study, there was no correlation between employment status, income and sexual function in the study of Elnashar et al. ${ }^{9}$ But, correlation was determined between economic status and sexual dysfunction in the study of Laumann et al. ${ }^{12}$ The reason behind why there was no correlation in Turkey might be associated with no huge difference in economic status of those in the study group.

\section{Conclusion}

These results indicate that SD is still common and is an important health problem. Therefore, it becomes crucial to evaluate symptoms and risk factors of SD, providing consultancy services about issues like preservation and treatment. Additionally, even though sexual health multi-dimensionally influences life of individuals, it is frequently ignored during the care given to patient. For this reason, maintaining sexual life which is a physiological need mostly stays in the background. Therefore, nurses, who are more together with individuals during health and every step of disease and treatment period, have important responsibilities especially about this issue. For this reason, it is recommended for nurses to play an active role in correct and sufficient data collection for sexual health history, evaluating the ratio of vulnerability of sexual health from disease period, providing an extensive care and diagnosing sexual problems and concerns. This way, it will contribute to improving life quality of women and preventing permanent health problems.

\section{Limitations}

There are some limitations to this study. First, the results obtained represent the women in the context of research and cannot be generalized. Second, the survey data were collected by face to face interviews. Asking questions about sexual life in our society, a topic may have been accepted as confidential, the replied reflect the current state of women working to take part. Therefore, the reliability of the data is limited to information provided by the interviewer.

\section{Acknowledgments}

Meral Kılıç would like to thank all of those who participated in this study.

\section{Authors' contribution}

MK was involved in study design, data collection, and manuscript development. MK, wrote the paper. MK performed the statistical analysis. MK read and approved the final manuscript

\section{Abbreviations}

SD: Sexual Dysfunction; FSF: Female Sexual Function Index; UI: Urinary Incontinence; FSD: Female Sexual Dysfunction

\section{References}

1. Arafa AE, Elbahrawe RS, Shawky SM, Mostafa AM, Ahmed SS, El-Houfey AA, et al. Risk factors associated with female sexual dysfunction among married women in Upper Egypt; a cross sectional study. International Journal Of Community Medicine and Public Health. 2018;52:449-53. 2. Kadri N, Alami KM, Tahiri SM. Sexual dysfunction in women: population based epidemiological study. Archives of Women's Mental Health. 2002;52:59-63. 
3. Lewis RW, Fugl-Meyer KS, Corona G, Hayes RD, Laumann EO, Moreira Jr ED, et al. Definitions/epidemiolo$\mathrm{gy} /$ risk factors for sexual dysfunction. The Journal of Sexual Medicine. 2010;74pt2:1598-607.

4. Kingsberg SA, Woodard T. Female sexual dysfunction: focus on low desire. Obstetrics \& Gynecology. 2015;1252:47786.

5. Sidi H, Puteh SEW, Abdullah N, Midin M. ORIGINAL RESEARCH-EPIDEMIOLOGY: The Prevalence of Sexual Dysfunction and Potential Risk Factors That May Impair Sexual Function in Malaysian Women. The Journal of Sexual Medicine. 2007;42:311-21.

6. Furukawa AP, Patton PE, Amato P, Li H, Leclair CM. Dyspareunia and sexual dysfunction in women seeking fertility treatment. Fertility and Sterility. 2012;986:1544-8. e2.

7. Anastasiadis AG, Davis AR, Ghafar MA, Burchardt M, Shabsigh R. The epidemiology and definition of female sexual disorders. World Journal of Urology. 2002;202:74-8.

8. Basson R, Berman J, Burnett A, Derogatis L, Ferguson D, Fourcroy J, et al. Report of the international consensus development conference on female sexual dysfunction: Definitions and classifications. Journal of Sex \& Marital Therapy. 2001;272:83-94.

9. Elnashar A, El-Dien Ibrahim M, El-Desoky M, Ali O, El-Sayd Mohamed Hassan M. Female sexual dysfunction in Lower Egypt. BJOG: An International Journal of Obstetrics \& Gynaecology. 2007;1142:201-6.

10. Aslan E, Beji NK, Gungor I, Kadioglu A, Dikencik BK. Prevalence and risk factors for low sexual function in women: a study of 1,009 women in an outpatient clinic of a university hospital in Istanbul. The Journal of Sexual Medicine. 2008;59:2044-52.

11. Walsh KE, Berman JR. Sexual dysfunction in the older woman. Drugs \& Aging. 2004; 2110:655-75.

12. Laumann EO, Paik A, Rosen RC. Sexual dysfunction in the United States: prevalence and predictors. JAMA. 1999;2816:537-44.

13. Berman JR, Adhikari SP, Goldstein I. Anatomy and physiology of female sexual function and dysfunction. European Urology. 2000;381:20-9.

14. Rosen CB, J. Heiman, S. Leiblum, C. Meston, R. Shabsigh, D. Ferguson, R. D'Agostino, R. The Female Sexual Function Index FSFI: a multidimensional self-report instrument for the assessment of female sexual function. Journal of Sex \& Marital Therapy. 2000;262:191-208.
15. Oksuz E, Malhan S. Prevalence and risk factors for female sexual dysfunction in Turkish women. The Journal of Urology. 2006;1752:654-8.

16. Wiegel M, Meston C, Rosen R. The female sexual function index FSFI: cross-validation and development of clinical cutoff scores. Journal of Sex \& Marital Therapy. 2005;311:1-20.

17. Ibrahim ZM, Ahmed MR, Ahmed WAS. Prevalence and risk factors for female sexual dysfunction among Egyptian women. Archives of Gynecology and Obstetrics. 2013;2876:1173-80.

18. Çayan S, Yaman Ö, Orhan I, Usta M, Başar M, Resim $\mathrm{S}$, et al. Prevalence of Sexual Dysfunction and Urinary Incontinence and Associated Risk Factors in Turkish Women. European Journal of Obstetrics \& Gynecology and Reproductive Biology. 2016.

19. Cayan S, Akbay E, Bozlu M, Canpolat B, lent u, Acar $\mathrm{D}$, et al. The prevalence of female sexual dysfunction and potential risk factors that may impair sexual function in Turkish women. Urologia Internationalis. 2004;721:52-7.

20. Du J, Ruan X, Gu M, Bitzer J, Mueck AO. Prevalence of and risk factors for sexual dysfunction in young Chinese women according to the Female Sexual Function Index: an internet-based survey. The European Journal of Contraception \& Reproductive Health Care. 2016;213:259-63. 21. Wolpe RE, Zomkowski K, Silva FP, Queiroz APA, Sperandio FF. Prevalence of female sexual dysfunction in Brazil: A systematic review. European Journal of Obstetrics \& Gynecology and Reproductive Biology. 2017;211:26-32. 22. Blümel JE, Chedraui P, Baron G, Belzares E, Bencosme A, Calle A, et al. Sexual dysfunction in middle-aged women: a multicenter Latin American study using the Female Sexual Function Index. Menopause. 2009;166:113948.

23. Safarinejad M. Female sexual dysfunction in a population-based study in Iran: prevalence and associated risk factors. International Journal of Impotence Research. 2006;184:382.

24. Çayan S, Yaman Ö, Orhan I, Usta M, Başar M, Resim $\mathrm{S}$, et al. Prevalence of sexual dysfunction and urinary incontinence and associated risk factors in Turkish women.

European Journal of Obstetrics \& Gynecology and Reproductive Biology. 2016;203:303-8.

25. Vahdaninia M, Montazeri A, Goshtasebi A. Help-seeking behaviors for female sexual dysfunction: a cross sec- 
tional study from Iran. BMC Women's Health. 2009;91:3. 26. Ismail SA, Abdel-Azim NE, Habib D, Zaky M, Saleh MA, Abbas AM. Prevalence, Risk Factors and Women's Attitude towards Female Sexual Dysfunction in Upper Egypt: Hospital based study.

27. Mostafa AM, Khamis Y, Helmy HK, Arafa AE, Abbas AM. Prevalence and patterns of female sexual dysfunction among overweight and obese premenopausal women in Upper Egypt; a cross sectional study. Middle East Fertility Society Journal. 2018;231:68-71.

28. Hamilton LD, Meston CM. Chronic stress and sexual function in women. The Journal of Sexual Medicine. 2013;1010:2443-54.

29. Emel E, Belgin A, ARSLAN SY, BİLGİLİ N. Sağl1klı kadınlarda cinsel fonksiyon bozukluğu sıklığ1 ve risk faktörleri. TÜBAV Bilim Dergisi. 2010;31:137-44.

30. Aslan E, Beji N, Gungor I, Kadioglu A, Dikencik B. Re: Prevalence and risk factors for low sexual function in women: A study of 1,009 women in an outpatient clinic of a university hospital in Istanbul—A response. The Journal of Sexual Medicine. 2009;65:1491-2.

31. Wallwiener CW, Wallwiener LM, Seeger H, Mück AO, Bitzer J, Wallwiener M. Prevalence of sexual dysfunction and impact of contraception in female German medical students. The Journal of Sexual Medicine. 2010;76:2139-48.

32. Fajewonyomi BA, Orji EO, Adeyemo AO. Sexual dysfunction among female patients of reproductive age in a hospital setting in Nigeria. Journal of Health, Population, and Nutrition. 2007;251:101.

33. Aslan G, Köseoğlu H, Sadik Ö, Gimen S, Cihan A, Esen A. Sexual function in women with urinary incontinence. International Journal of Impotence Research. 2005;173:248.

34. Salonia A, Zanni G, Nappi RE, Briganti A, Dehò F, Fabbri F, et al. Sexual dysfunction is common in women with lower urinary tract symptoms and urinary incontinence: results of a cross-sectional study. European urology. 2004;455:642-8.

35. Caruso S, Brescia R, Matarazzo MG, Giunta G, Rapisarda AMC, Cianci A. Effects of Urinary Incontinence Subtypes on Women's Sexual Function and Quality of Life. Urology. 2017;108:59-64. PubMed

36. Handa VL, Harvey L, Cundiff GW, Siddique SA, Kjerulff $\mathrm{KH}$. Sexual function among women with urinary incontinence and pelvic organ prolapse. American Journal of Obstetrics and Gynecology. 2004;1913:751-6.

37. Karbage SA, Santos ZM, Frota MA, de Moura HJ, Vasconcelos CT, Neto JAV, et al. Quality of life of Brazilian women with urinary incontinence and the impact on their sexual function. European Journal of Obstetrics \& Gynecology and Reproductive Biology. 2016;201:56-60.

38. Zincir H, Demir G, Ozen B. Sexual Dysfunction in Married Women With Urinary Incontinence. Urology Journal. 2018;154:193 PubMed -8.

39. Grzybowska ME, Wydra D. Predictors of sexual function in women with stress urinary incontinence. Neurourology and Urodynamics. 2018;372:861-8.

40. dos Santos KM, Da Roza T, da Silva LL, Wolpe RE, da Silva Honório GJ, da Luz SCT. Female sexual function and urinary incontinence in nulliparous athletes: An exploratory study. Physical Therapy in Sport. 2018;33:21-6. 41. El Atrash G, Ali MH, Abdelwahab HA, Abdelreheem LA, Shamaa M. The assessment of sexual dysfunction in Egyptian women with lower urinary tract symptoms. Arab Journal of Urology. 2014;123:234-8.

42. Jiann BP, Su CC, Yu CC, Wu TT, Huang JK. Risk factors for individual domains of female sexual function. The Journal of Sexual Medicine. 2009;612:3364-75.

43. Hassanin IM, Helmy YA, Fathalla MM, Shahin AY. Prevalence and characteristics of female sexual dysfunction in a sample of women from Upper Egypt. International Journal of Gynecology \& Obstetrics. 2010;1083:219-23. 44. Jaafarpour M, Khani A, Khajavikhan J, Suhrabi Z. Female sexual dysfunction: prevalence and risk factors. Journal of Clinical and Diagnostic Research: JCDR. 2013;712:2877. 45. Zhang H, Yip PS. Female sexual dysfunction among young and middle-aged women in Hong Kong: Prevalence and risk factors. The Journal of Sexual Medicine. 2012;911:2911-8.

46. Baksu B, Davas I, Agar E, Akyol A, Varolan A. The effect of mode of delivery on postpartum sexual functioning in primiparous women. International Urogynecology Journal. 2007;184:401-6.

47. Safarinejad MR, Kolahi AA, Hosseini L. COUPLES'SEXUAL DYSFUNCTIONS: The Effect of the Mode of Delivery on the Quality of Life, Sexual Function, and Sexual Satisfaction in Primiparous Women and Their 
Husbands. The Journal of Sexual Medicine. 2009;66:1645-67. 48. Chien L-Y, Tai C-J, Hwang F-M, Huang C-M. Postpartum physical symptoms and depressive symptomatology at 1 month and 1 year after delivery: A longitudinal questionnaire survey. International Journal of Nursing Studies. 2009;469:1201-8.

49. Barrett G, Pendry E, Peacock J, Victor C, Thakar R, Manyonda I. Women's sexual health after childbirth. BJOG: An International Journal of Obstetrics \& Gynaecology.
2000;1072:186-95.

50. Lurie S, Aizenberg M, Sulema V, Boaz M, Kovo M, Golan A, et al. Sexual function after childbirth by the mode of delivery: a prospective study. Archives of Gynecology and Obstetrics. 2013;2884:785-92.

51. Glazener CM. Sexual function after childbirth: women's experiences, persistent morbidity and lack of professional recognition. BJOG: An International Journal of Obstetrics \& Gynaecology. 1997;1043:330-5. 